\title{
$O$ desempenho de um serviço de atenção primária à saúde na perspectiva da inteligência coletiva
}

\section{dossiê}

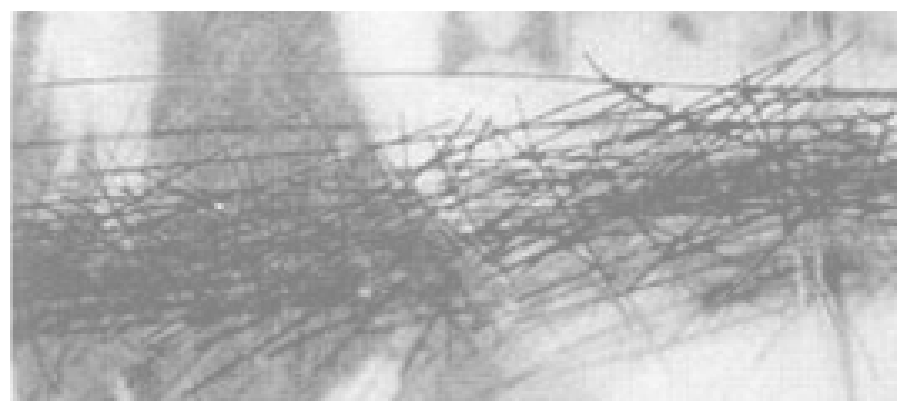

Ricardo Rodrigues Teixeira ${ }^{1}$

TEIXEIRA, R. R. The performance of primary healthcare from the perspective of collective intelligence. Interface Comunic., Saúde, Educ., v.9, n.17, p.219-34, mar/ago 2005.

The purpose of this article is to explore some of the possible contributions of the emerging field of Collective Intelligence to Healthcare investigations, in particular to the examination of the actions of healthcare services. To this end, a brief review of the general and specific literature on the subject is necessary, from which one can extract elements for outlining a first level of studies in the healthcare field, from this perspective. We also try to highlight the connection of this level of studies with the problems of the field of Collective Health, widely explained already. Finally, we discuss its ethical and political implications.

KEY WORDS: collective intelligence; public healthcare; healthcare services; primary attention to healthcare.

Este artigo visa explorar alguns possíveis aportes do emergente campo da Inteligência Coletiva para a investigação em Saúde, em particular para a investigação sobre a ação dos serviços de saúde. Para isso faz-se uma breve revisão da literatura geral e mais específica sobre o assunto e dela extraem-se elementos para esboçar um primeiro plano de estudos desta perspectiva na área da Saúde. Também procura-se destacar a vinculação deste plano de estudos com problemas já bem colocados no campo da Saúde Coletiva, discutindo, por fim, suas implicações ético-políticas.

PALAVRAS-CHAVE: inteligência coletiva; saúde pública; serviços de saúde; atenção primária à saúde.

\footnotetext{
${ }^{1}$ Docente e pesquisador, Centro de Saúde Escola Samuel Barnsley Pessoa, Departamento de Medicina Preventiva, Faculdade de Medicina, Universidade de São Paulo, São Paulo, SP. <ricarte@usp.br>
}

Av. Vital Brasil, 1490.

São Paulo, SP

05503-000 
Este artigo visa explorar alguns possíveis aportes do emergente campo da Inteligência Coletiva (IC) para a investigação em Saúde, em particular para a investigação sobre a ação dos serviços de saúde, apresentando uma proposta de estudo que busca desenvolver critérios para a avaliação do desempenho de serviços de Atenção Primária à Saúde (APS) desta perspectiva.

Introdutoriamente, pode-se dizer que este novo campo de pesquisa transdisciplinar está centrado no estudo da "potência de ação coletiva" dos grupos e que toma como hipótese principal que esta "potência" depende fundamentalmente da capacidade de indivíduos e grupos interagirem, pondo-se em relação e, desta forma, produzirem, trocarem e utilizarem conhecimentos. Em sentido ampliado, o campo de estudos $e$ intervenções da IC pode ser dito uma "transdisciplina" que visa permitir o diálogo dos saberes sobre o homem para melhor compreender $e$, idealmente, melhorar os processos de aprendizagem e criação nas coletividades locais, bem como no interior de redes cooperativas de todo tipo, organizadas a partir das mais variadas tecnologias sociais.

\section{O emergente campo da Inteligência Coletiva}

O tema da IC vem sendo objeto de numerosos trabalhos ao longo dos últimos cinqüenta anos, com uma nítida aceleração nesses dez anos mais recentes. É possível reconhecer claramente que uma idéia comum vem sendo elaborada em conceitos tão diversos como o de "noosfera" (Teilhard de Chardin, 1955), "ecologia da mente" (Bateson, 1972), "epidemiologia das representações" (Sperber, 1996), cybionte (Rosnay, 1997), hive mind (Kelly, 1994), "inteligência conectiva" (Kerckhove, 1997) ou super-brain (Heylighen, 1998), entre tantos outros.

Para melhor aquilatarmos a força dessa emergência epistemológica, cabe destacar alguns desenvolvimentos significativos que vêm se dando em diversas disciplinas e campos de pesquisa e que, de múltiplas formas, alimentam ou convergem para os estudos sobre a IC humana. Na biologia, por exemplo, identifica-se um grande esforço para aproximar a noção de sistema de comunicação complexa auto-organizada do conceito de sistema cognitivo, como nas pesquisas de Atlan (1972) sobre a organização biológica e a teoria da informação, ou nos estudos de Maturana \& Varela (1984) sobre o caráter "autopoiético" do vivo, buscando "conhecer o conhecer" deste ponto de vista. Estes últimos autores, em particular, contribuíram enormemente para que se chegasse a um conceito de inteligência como uma "potência de auto-criação" (Lévy, 2002).

As ciências cognitivas, por seu lado, também vêm contribuindo para a construção de uma idéia de IC quando insistem, cada vez mais, no estudo de propriedades cognitivas emergindo de fenômenos coletivos. Identifica-se esta abordagem tanto na concepção de "sociedade da mente" de Minsky (1997), quanto nos experimentos de Langton (1989) que simulam formas de "vida artificial", situando-se a meio caminho entre as ciências cognitivas, a ecologia teórica e a teoria da evolução.

Também no campo das ciências da economia e da gestão é possível identificar, e bem precocemente, uma nítida polarização em direção ao tema da IC e de modo bastante significativo - não se pode negar - nas 
formulações de alguns expoentes do pensamento liberal. São exemplos importantes tanto a "economia do conhecimento" de Hayek (1945) com sua idéia de uma "ordem espontânea emergindo de uma complexa rede de interações", quanto, mais recentemente, a idéia de "capital social" (confiança e qualidade dos laços sociais) como fundamento da prosperidade, defendida por Fukuyama (1996). Sem falar no crescimento fulgurante nos últimos quinze anos do knowledge management e das teorias sobre "organizações que aprendem", seja em abordagens mais "clássicas" (Morey et al., 2000), seja em outras menos convencionais (Levin et al., 2000).

As ciências sociais igualmente têm dado sua contribuição à compreensão dos fenômenos de IC, como é exemplo a teoria das sociedades como sistemas auto-organizados (Luhmann, 1989), mas também, e muito

significativamente, os recentes desenvolvimentos da sociologia e da história das ciências (Latour, 2000; Stengers, 1993; Callon, 1989) que, ao elucidarem os processos efetivos de produção de conhecimento na comunidade científica, vêm fornecendo preciosas indicações sobre os mecanismos concretos de IC num campo crucial.

Por fim, algumas das contribuições mais fundamentais têm origem na filosofia e antropologia, especialmente aquelas que advogam serem as técnicas constitutivas de uma IC da humanidade em constante transformação (Deleuze \& Guattari, 1995/1997; Serres, 1968; LeroiGourhan, 1964; Simondon, 1958). Uma concepção bastante assemelhada pode ser encontrada em estudos situados na interface das ciências da comunicação com a antropologia que, partindo dos trabalhos de McLuhan (1964), examinaram as mutações culturais ligadas às transformações nos sistemas de comunicação (Havelock, 1996; Goody, 1987). Todos esses filósofos, antropólogos e estudiosos da comunicação constituem referências fundamentais para as formulações de Lévy em torno dos conceitos de "tecnologias da inteligência" (1993) e "inteligência coletiva" (1998).

Esta lista está longe de ter sido esgotada e outros conceitos e autores importantes ainda serão convocados mais adiante. Lévy, entretanto, merece um especial destaque, por se tratar de um autor decisivo para o aprofundamento e a disseminação desse campo problemático, sendo ademais um dos principais responsáveis pela sua difusão sob a designação, afinal, aqui adotada, de "inteligência coletiva". Em relação à possibilidade, que ora apresentamos, de se estender esta perspectiva de estudos ao campo da Saúde, sua influência também foi determinante e se deu não apenas por meio de sua produção escrita, mas também pessoalmente, graças a algumas oportunidades privilegiadas de conversações entretidas no final da década passada, uma delas registrada, comentada e publicada neste periódico (Teixeira, 1999).

É em Lévy que encontramos uma primeira e formidável síntese de vários dos conhecimentos disciplinares acima apresentados, que nos serviu como um ponto de partida luminoso para os desdobramentos que vimos operando para pensar as questões da Saúde. É dele a definição, já citada, de inteligência como uma "potência de auto-criação".

Em termos cognitivos, ela se traduz por uma capacidade de aprendizagem autônoma e, em termos históricos, por um processo de 
TEIXEIRA, R. R.

evolução. A inteligência emerge de processos de interação circulares e autoprodutores entre um grande número de sistemas complexos. Assim, um ecossistema, uma espécie viva, uma sociedade animal, uma sociedade humana, um organismo, um sistema imunológico ou um cérebro podem ser ditos 'inteligentes'. Com efeito, eles estão engajados, com seus ambientes, em processos entrecruzados de auto-produção e de evolução (ou de aprendizagem).

A inteligência é sempre o fato de um coletivo numeroso e interdependente: coletivo de idéias, pensamentos, módulos cognitivos, neurônios, células, organismos, espécies etc. O termo 'inteligência coletiva' é, portanto, um pleonasmo. Mas, como nossos preconceitos culturais nos inclinam a imaginar que a inteligência seria a propriedade de indivíduos, eu prefiro acrescentar o adjetivo 'coletivo', a fim de qualificar corretamente a potência de auto-criação, seja ela biológica ou cultural (Lévy, 2002).

Mas a IC humana ainda merece ser distinguida dessa IC largamente distribuída na natureza, uma vez que com a humanidade surge uma velocidade e uma intensidade de auto-criação inéditas entre as sociedades animais.

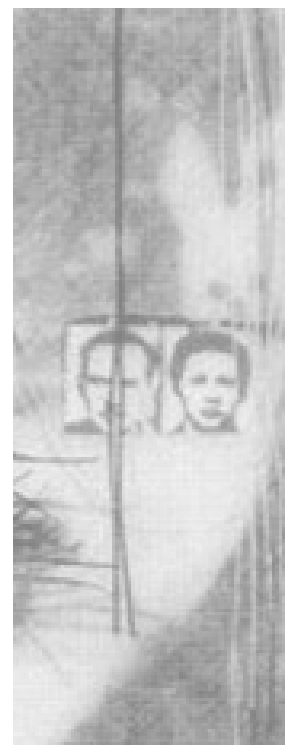

\begin{abstract}
...a linguagem e engenhosidade cooperativa do homo sapiens the permitiram desenvolver um ritmo de invenção (e de mecanismos de transmissão das invenções) desconhecido das sociedades de abelhas, formigas ou mamíferos. Além disso, contrariamente à sociedade de insetos, a inteligência coletiva humana aumenta com a liberdade e a responsabilidade de seus membros e, em contrapartida, os enriquece.

Só os seres humanos, no reino animal, são capazes de aprender enquanto espécie. É o próprio significado da cultura. Porque é cultural, a inteligência coletiva humana se aperfeiçoa. Ela trabalha, e cada vez mais deliberadamente, para sua própria melhoria. As grandes religiões éticas e universalistas, as filosofias, os movimentos de emancipação política, a inventividade econômica, o direito e o empreendimento tecnocientífico trabalham todos, cada um de uma maneira diferente, para aumentar a potência humana ou, dito de outra forma, suas capacidades de inteligência coletiva. (Lévy, 2002)
\end{abstract}

Se, de um modo ou de outro, a história humana é a história deste aumento da "potência de ação coletiva", agora, sob o paradigma da IC, nos está dado trabalhar deliberadamente para aumentá-la.

\title{
Alguns outros conceitos $e$ categorias-chave para entender a ação coletiva
}

Se as instigantes formulações de Lévy foram o ponto de partida, a elaboração de um plano concreto de estudos no campo da saúde passou pela incorporação de outras abordagens, mais uma vez advindas de uma multiplicidade de campos disciplinares (economia, sociologia, antropologia, filosofia, ciências da informação e da comunicação), todas trazendo 
contribuições importantes para uma compreensão em profundidade da ação coletiva humana.

Seguindo uma sistematização elaborada por Costa (2004), estas diferentes contribuições podem ser agrupadas sob as seguintes categorias ou campos problemáticos: a assimetria na relação indivíduo/grupo, o jogo das preferências individuais, a noção de capital social, a noção de comunidade e o desenvolvimento das redes digitais. Todas tocam em questões de vivo interesse para a construção de um plano de investigações (especialmente para um plano de investigações empíricas) e serão brevemente comentadas a seguir.

Primeiramente, temos que nos últimos trinta anos houve um avanço considerável das pesquisas desenvolvidas no cruzamento da economia com a sociologia, no sentido de reconhecer uma assimetria no modo como se comportam os indivíduos, quer atuem em grupo, quer atuem isoladamente. Classicamente, a sociologia e a economia trabalham com a idéia mais próxima do senso comum de que haveria um prolongamento natural dos interesses individuais no contexto de grupos. No entanto, nada garante que todos os indivíduos de um mesmo grupo agirão para atingir um determinado objetivo, mesmo que todos ganhassem com isso e mesmo sendo todos, indivíduos racionais e centrados em seus próprios interesses (Olson, 1999). Esse reconhecimento é de crucial importância para uma compreensão mais adequada de problemas fundamentais no campo da Saúde, como aqueles relacionados à tomada de decisão ou à adesão dos

${ }^{2}$ Em seu Essai sur l'application de l'analyse à la probabilité des décisions rendues à la pluralité des voix, Condorcet, preocupado com o problema da eleição pelo voto popular, procurava enfrentar matematicamente o problema da construção da opinião geral a partir das opiniões individuais. Se o problema encontra uma solução simples quando se trata de duas pessoas, para além de duas, o problema adentra situações paradoxais. Condorcet entreviu que para resolver conflitos de opinião com o intuito de construir uma opinião geral seria preciso admitir um princípio exterior (por ele chamado de princípio majoritário). Para conhecer melhor o "método de Condorcet", ver este verbete na enciclopédia livre Wikipedia: http:// en.wikipedia.org/wiki/ Condorcet_method. indivíduos às inovações (idéias, comportamentos, normas etc.). Indivíduos tomam decisões sobre sua participação numa ação coletiva condicionados por fatores que não se reduzem a seus próprios interesses e preferências (Granovetter, 1995), assim como a adesão dos indivíduos às inovações não depende exclusivamente de preferências pessoais, mas requer, além disso, uma negociação dentro da dinâmica do coletivo no qual estão inseridos (Valente, 1996).

O reconhecimento dessa assimetria e de que o comportamento dos indivíduos atuando em grupo depende de uma negociação que se dá dentro da dinâmica do coletivo nos conduz a um outro problema estreitamente relacionado que é o do chamado jogo das preferências individuais. Este problema absolutamente não é novo e já estava, de certa forma, colocado na "matemática social" do Marquês de Condorcet, no final do século XVIII². Hoje, entretanto, este se coloca com uma força ainda maior, na medida em que as trocas sociais se intensificam e, cada vez mais, nos mais variados contextos, as preferências individuais são levadas a se confrontar. De fato, como afirma Costa (2004), "todo tipo de grupo, comunidade, sociedade é fruto de uma árdua e constante negociação entre preferências individuais" - sem esquecer que, "via de regra, as preferências ditas 'individuais' são na verdade fruto de uma construção coletiva, num jogo constante de sugestões $e$ induções que constitui a própria dinâmica da sociedade".

Ora, o alcance desta discussão para o enfrentamento de tantas outras questões centrais para o campo da Saúde também é dos mais evidentes e é de fundamental importância compreender esse jogo de preferências e suas 
implicações, tais como aquelas que estariam relacionadas às negociações que se dão nos serviços de saúde. É preciso compreender qual o estado das negociações entre as pessoas num dado grupo, num dado momento: se ele é precário, como nas situações extremas de violência social generalizada, ou se ele é rico, quando o nível de confiança dentro do grupo é elevado e suas ações coletivas são potentes.

Uma das mais fecundas abordagens para o tratamento destas questões talvez possa ser encontrada nos estudos centrados na noção de capital social. Isso porque o capital social de uma comunidade pode ser entendido como...

...a capacidade de interação dos indivíduos, seu potencial para

interagir com os que estão a sua volta, com seus parentes, amigos, colegas de trabalho, mas também com os novos vizinhos, com alguém novo no bairro ou no trabalho etc. Quanto mais um indivíduo interage com outros, mais ele está apto a reconhecer comportamentos, intenções, valores, competências $e$ conhecimentos que compõem seu meio. Inversamente, quanto menos alguém interage (ou interage apenas num meio restrito), menos tenderá a desenvolver plenamente essa habilidade fundamental que é a percepção do outro. Ora, um dos aspectos essenciais para a consolidação de projetos coletivos, projetos que necessitam do engajamento de muitos em ações específicas é, sem dúvida, o sentimento de confiança mútua que precisa existir em maior ou menor escala entre as pessoas. A construção dessa confiança está diretamente relacionada com a capacidade que cada um teria de entrar em relação com os outros, de perceber o outro e incluí-lo em seu universo de referência. (Costa, 2004)

Esta constatação é intuitiva, é algo claramente sentido e experimentado por todos nós, antes mesmo de se tornar inteligível e empiricamente demonstrável. No entanto, o interesse maior pelos estudos de capital social decorre exatamente do esforço que vem sendo realizado nessa área para produzir indicadores empíricos dessa realidade (Grootaert et al., 2003). As mensurações do capital social baseiam-se justamente no levantamento do grau das interações entre as pessoas num determinado grupo ou comunidade. Envolvem também avaliações qualitativas que consideram a forma como cada indivíduo reconhece no outro algo que lhe é familiar, mas também como reconhece no outro, as diferenças. Esse estado das relações entre os indivíduos num grupo, seja ele avaliado quantitativa ou qualitativamente, pode vir a se constituir num sensível índice de referência da potência de ação coletiva inteligente daquele grupo.

Além disso, essa linha de estudos apresenta alguns outros pontos de grande interesse para a construção de projetos de investigação empírica no campo da Saúde. Importantes estudos nesta área (Putnam, 1993; Coleman, 1990) ressaltam o papel e a influência das instituições como mediadoras da interação social, uma vez que promovem (ou não) valores de integração $e$ confiança entre os indivíduos e os grupos. Isso faz com que o levantamento 
do capital social seja também um meio de se perguntar sobre o papel das instituições (de saúde): elas estariam funcionando realmente como mediadoras? Que tipo de relações humanas têm efetivamente promovido? Têm servido mais ao controle da sociedade ou têm trabalhado para o seu fortalecimento?

Por fim, também é interessante ressaltar como há uma circularidade na lógica que une capital social e ação coletiva, especialmente útil de se compreender quando se pensa em intervenções para incrementar a IC dos grupos. É preciso capital social, isto é, um verdadeiro patrimônio de interrelação humana, para se ampliar a potência das ações coletivas, mas, por outro lado, essas ações, como conseqüência, não cessam de enriquecer o patrimônio de inter-relação humana, não cessam de aumentar o capital social. O capital social, assim como outras modalidades de capital "imaterial", possui essa característica sui generis que faz com que seu uso não seja equivalente ao seu gasto e sim ao seu incremento.

Todas essas questões relacionadas às interações entre os indivíduos e, em última instância, à qualidade do vínculo social, trazem à tona um outro tema central que tem sido submetido a um aggiornamento substantivo pela sociologia contemporânea: o conceito de comunidade. Do ponto de vista da IC, o que interessa não é a desgastada discussão a respeito se ainda há ou não comunidades nas sociedades industriais avançadas ou se havia ou não comunidades coesas e solidárias nas sociedades tradicionais, mas qual são os modos efetivos que temos encontrado de "fazer comunidade". Determinados segmentos da sociologia têm oferecido uma alternativa conceitual e analítica extremamente enriquecedora com a noção de redes sociais. Particularmente os chamados "analistas estruturais de redes" (Wasserman \& Faust, 1999; Wellman \& Berkowitz, 1988), argumentam que a comunidade jamais desapareceu, mas foi transformada. Para enxergála, é preciso focar a atenção nos laços sociais e nos sistemas informais de trocas de benefícios e não apenas em relações de vizinhança e parentesco, que constituem as chamadas "comunidades tradicionais". Tratar as comunidades como redes sociais permite perceber que as "comunidades tradicionais" correspondem apenas a um dentre os muitos padrões possíveis, assim como tem permitido aos analistas examinar o modo como determinadas transformações sociais têm produzido padrões alternativos de trocas e fluxos de benefícios entre os indivíduos e os grupos.

Não é difícil estimar o alcance dessa mudança de perspectiva para, por exemplo, fazer-nos rever certas concepções correntes sobre família $e$ comunidade no campo da Saúde, ainda muito tributárias de uma visão "tradicional" e idealizada de comunidade. Não se trata, evidentemente, de decretar o fim das comunidades fundadas em relações de parentesco $e$ proximidade, como já foi dito acima, mas de nos apropriarmos deste outro referencial, que facilita uma ligação analítica das redes comunitárias mais "tradicionais" com outras estruturas de interação, como as relações de trabalho, as relações estabelecidas ou propiciadas por inúmeras instituições sociais (como, por exemplo, os serviços de saúde) ou pelas novas tecnologias de comunicação (como, por exemplo, as redes digitais).

Finalmente, a compreensão das mudanças em curso promovidas por estas 
últimas tecnologias constitui ainda um outro passo decisivo para uma adequada aproximação teórico-prática do problema da IC. Aqui os estudos e abordagens multiplicam-se vertiginosamente e não saberíamos açambarcar nem uma fração das produções consideradas relevantes. Por ora, o importante é destacar que não são as inúmeras pesquisas nesta área - que vêm elucidando diversos aspectos da lógica da ação coletiva -, as únicas que interessam, mas o fato de que os meios digitais têm oferecido uma possibilidade real de se mensurar e cartografar dinamicamente a própria ação coletiva. Esse aspecto tem sido decisivo para a elaboração de um programa de investigações em IC, tal como vem sendo proposto por Lévy e que inclui centralmente procedimentos cartográficos baseados em softwares de rede ${ }^{3}$. E não é só o projeto de Lévy: também os analistas estruturais de redes têm se beneficiado das tecnologias digitais para empreender o estudo de redes grandes e complexas ${ }^{4}$. Em suma, para o desenvolvimento de um plano de estudos de IC em Saúde, há muito que se aprender com as redes digitais, não apenas a respeito da lógica da ação coletiva e da formação de "comunidades virtuais", mas também como a utilização destas tecnologias pode contribuir para o próprio estudo das redes e dos padrões de interação coletiva.

Como foi dito no princípio, esses campos problemáticos, conceitos e categorias analíticas têm sido extremamente úteis para que um conjunto de preocupações $e$ interesses mais gerais possam progressivamente "tomar corpo" num desenho de investigações empíricas mais situado. Contudo, ainda vislumbramos a possibilidade de todas essas abordagens serem criticamente reavaliadas à luz de considerações introduzidas pela filosofia política.

De fato, já há alguns anos que vimos produzindo toda uma elaboração filosófica para pensar questões de Saúde que, pouco a pouco, tem convergido para este universo problemático da IC. Trata-se, sobretudo, dos aportes valiosos oferecidos pela filosofia prática de Espinosa e, mais recentemente, pelos ensaios de filosofia política de Hardt \& Negri (2004) em torno do tema da "multidão". Não há espaço para aprofundarmos essa discussão neste momento, mas alguns produtos destas aproximações com o campo da Saúde já estão disponíveis (Teixeira, 2004a; 2004b). O modo como estas reflexões podem vir a ser destiladas num plano de investigações concreto será brevemente comentado até o final deste artigo.

\section{Inteligência Coletiva e Saúde Coletiva}

Um primeiro plano de pesquisas de IC no campo da Saúde começou a se delinear, ao se buscar integrar alguns dos modelos de estudo acima discutidos. Por um lado, consideramos os principais recursos raros que compõem o "capital de inteligência coletiva" de uma comunidade e que poderiam ser representados por três capitais distintos em relação de interdependência: o capital técnico, o capital social e o capital cultural. Por outro, tomamos o paradigma da rede, que permitiria reunir sob os mesmos conceitos formais (laços e nós) as tecnologias sociais (capital técnico), a análise sócio-política das redes de pessoas (capital social) e a análise cultural e cognitiva das redes semânticas registradas ou a memória da comunidade
${ }^{3}$ A principal referência é, sem dúvida, o projeto das Árvores de Conhecimentos desenvolvido por Lévy e Authier (1995):

"método

informatizado para o gerenciamento global das competências nos estabelecimentos de ensino, empresas,

bolsas de emprego, coletividades globais e associações”. Para conhecer o software desenvolvido para gerar o mapa dinâmico das competências (SEE-K ${ }^{\circledR}$ ), ver $<w w w$.trivium. fr $>$.

${ }^{4}$ Para conhecer alguns softwares livres que vêm sendo desenvolvidos para apoiar a análise estrutural de redes, ver <http://

www.stanford.edu/ group/esrg/ siliconvalley/ home.htm>. 
(capital cultural). A idéia básica, então, seria proceder à cartografia das redes técnicas, sociais e culturais que caracterizariam a IC da comunidade.

Considerando-se, entretanto, que a construção desse plano de pesquisas, a despeito de sua originalidade, deveria estar rigorosamente pautada pelo princípio da eficácia investigativa, procuramos não reinventar a roda $e$ decidimos fazê-lo derivar dos acúmulos teórico-práticos já produzidos nas investigações próprias ao campo da Saúde. Assim, reconhecemos nas atuais propostas de investigação da IC no campo da Saúde, um desdobramento de certas linhas ou problemas de investigação da Saúde Coletiva que vêm sendo desenvolvidas nos últimos anos, com destaque para: 1 os conhecimentos acumulados em torno do conceito de tecnologias de organização do trabalho em saúde (Schraiber et al., 1996; Mendes-Gonçalves, 1994) e o reconhecimento da importância das chamadas tecnologias da relação, também chamadas de "tecnologias leves", para compreendermos a substância do trabalho em saúde (Merhy, 1997); 2 as releituras que a psicologia cognitiva, a microssociologia, a comunicação e a semiótica nos permitiram fazer do trabalho em saúde e que nos conduziram a evidenciar sua natureza eminentemente conversacional (inclusive reconhecendo a mobilização no trabalho em saúde de diferentes técnicas de conversa) e à proposição teórica de pensar os serviços de saúde como redes de conversação (Teixeira, 2003); 3 a consideração das dimensões subjetivas e afetivas do trabalho em saúde, que vêm conduzindo, mais recentemente, a uma reflexão em profundidade sobre a qualidade do encontro nas práticas de saúde e têm colocado em primeiro plano temas como o do acolhimento nos serviços de saúde (Teixeira, 2005, 2004a, 2004b, 2001; Ayres, 2001).

A proposta de investigação que apresentaremos a seguir pode ser entendida como uma primeira tentativa de produzir uma fecundação recíproca entre os acúmulos teórico-metodológicos oriundos dos estudos de IC (particularmente aqueles referentes aos métodos e técnicas de cartografia de redes) e toda uma linhagem de investigações e intervenções tecno-políticas nos serviços de saúde que vem se desenvolvendo no campo da Saúde Coletiva brasileira.

Como nossa proposta de investigação dirige-se a um campo empírico bastante específico, que são os serviços de Atenção Primária à Saúde (APS), também cabe ressaltar algumas características deste tipo de serviços que fazem dele um campo de estudos privilegiado. Já produzimos recentemente, para uma outra publicação, uma síntese destas características, que se presta perfeitamente para os esclarecimentos que se fazem necessários no presente contexto; por isso, citamo-la. São características fundamentais da APS:

1 a extensão e capilaridade da rede de serviços de atenção primária à saúde, que não encontra paralelo em nenhum outro equipamento da rede; 2 sua atuação referida às demandas de saúde mais freqüentes, que se encontram muitas vezes na fronteira entre os "problemas da vida" e a "patologia" objetivamente definida e que, portanto, nem sempre estão claramente configuradas como demandas cuja resposta mais adequada possa ser encontrada exclusivamente no arsenal diagnóstico-terapêutico da biomedicina; desta última característica decorrem duas outras, fundamentais: $2 \mathrm{a}$ a importância excepcional que adquire neste espaço [as 
chamadas] "tecnologias de escuta e de negociação das regras comportamentais e organizacionais" ou, em outras palavras, a importância das "tecnologias de conversa" que facilitariam a identificação, elaboração e negociação com os usuários das necessidades que podem vir a ser satisfeitas naquele ou em outros espaços institucionais; e $2 \mathrm{~b}$ a importância da ação multiprofissional e da articulação intersetorial, já que a atenção primária possui inevitavelmente essa vocação de "porta de entrada" não apenas para a rede de serviços de saúde, mas para uma multiplicidade de outras demandas sociais, que acabam por se traduzir em demandas de saúde ou simplesmente aí se apresentam pela ausência de outros espaços sociais de expressão (Teixeira, 2005).

\section{Uma proposta de investigação em Saúde e Inteligência Coletiva} Chegamos assim, finalmente, a um projeto de pesquisa composto de três momentos de inovação tecnológica (uma tecnologia da relação, uma tecnologia de organização do trabalho, um conjunto de tecnologias de informação e comunicação) e um momento principal de estudo do desempenho deste arranjo tecnológico.

O primeiro momento de inovação tecnológica está relacionado ao processo de concepção, formalização e divulgação, por um conjunto de trabalhadores de um serviço de APS - o Centro de Saúde Escola Samuel Barnsley Pessoa / Butantã (CSEB) -, de uma dada tecnologia da relação entendida como "um certo modo de acolher" o cidadão que vem ao serviço. Nesse processo, lançamos mão da antropologia visual, em combinação com um conjunto de técnicas pedagógicas e artísticas, acreditando estar fornecendo um conjunto de procedimentos técnicos e metodológicos bastante potentes para intervir num grupo, no momento em que ele deseja problematizar e refletir sobre uma prática já desempenhada, auxiliando-o a produzir enunciados e a formalizá-la enquanto uma autêntica tecnologia da relação. No caso, o chamado acolhimento. Esse processo de formalização se conduzirá de tal modo a que possa ser "mostrado" visualmente e, desta forma, torne-se, ao mesmo tempo, transferível e documentado.

O segundo momento de inovação tecnológica desenvolve-se sobre camadas de inovações tecnológicas anteriores, situadas no campo das tecnologias de organização do trabalho em saúde (que conduziram a organização do trabalho assistencial do CSEB à sua configuração atual) e no campo das tecnologias de informação (que permitem há vários anos que geremos informação consolidadas sobre o desempenho deste trabalho). Neste momento, a tecnologia de organização do trabalho se apresenta como estando dada e é aqui tomada em sua expressão enquanto uma rede de conversações. A inovação, neste caso, incide mais exatamente no campo das tecnologias de informação, no sentido de ampliar as possibilidades de avaliação do desempenho do trabalho coletivo, valorizando mais as relações, as conexões, os fluxos que se estabelecem entre diferentes "nós" da rede. Com isso, pretende-se estar reunindo as condições para se produzir uma cartografia da rede de conversações do CSEB.

O terceiro momento de inovação tecnológica também está relacionado ao campo das tecnologias de informação e comunicação e também consiste 


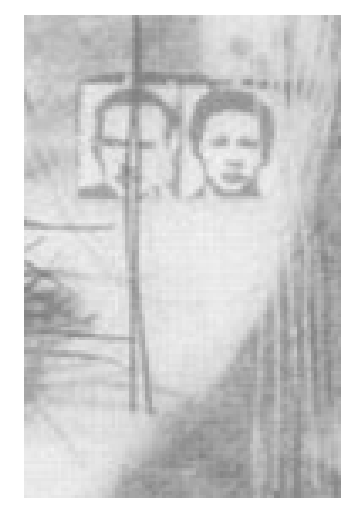

na produção de uma cartografia da rede, apenas que, dessa vez, da chamada rede de redes de conversações. Trata-se do projeto de reconhecimento da rede de outras instituições com as quais o serviço de APS em questão está de alguma forma articulado. A estratégia prevista consiste num amplo processo de visitação de cerca de meia centena de outras instituições (públicas, privadas, de saúde ou de outros setores) por duplas de trabalhadores do serviço, munidos de um roteiro de observação. As informações reunidas, além de permitirem retraçar a rede de instituições com as quais o serviço se articula pela via do trabalho assistencial, devem mais imediatamente servir para a construção de uma espécie de "Guia de Cidadania e Serviços". Este guia informatizado, disponível para consulta em todos os setores do serviço, representa um dado uso das tecnologias de informação e comunicação considerado decisivo para se alcançar o tipo de desempenho institucional que se quer aqui observar e analisar.

Concluído este processo de desenvolvimento e composição tecnológica, pretendemos avaliar o desempenho deste dispositivo segundo critérios que nos são fornecidos pela ampla gama de estudos que foram acima apresentados e rapidamente comentados. A estratégia básica será fazer um estudo prospectivo de uma coorte de usuários novos do CSEB, acompanhando suas trajetórias pela rede de conversações do serviço e, eventualmente, pela rede de rede de conversações à qual o serviço se articula, explorando ainda suas múltiplas conexões com as demais redes sociais a que pertencem esses usuários. Pela leitura dos registros de atendimentos, de questionários aplicados em diferentes momentos da "trajetória" (fixada em cerca de 12 meses) e de entrevistas semiestruturadas com uma fração desses indivíduos, selecionados desta coorte por critérios precisos, pretendemos estar aptos a responder se o serviço em questão capacita, habilita, instrumentaliza mental e afetivamente os indivíduos de uma determinada população (usuária do serviço), de tal forma a ampliar sua capacidade de se pôr em relação, isto é, sua capacidade de interação, formação de comunidade, empoderamento, expansão de suas potencialidades $e$ singularização existencial. Argumentamos que, desse modo, são postos em evidência dimensões e aspectos fundamentais para o entendimento do que possa significar, por exemplo, o desafio da humanização do sus.

Todo este processo de reconhecimento do tipo de dispositivo tecnológico que se pretende examinar da perspectiva da Inteligência Coletiva tem, ainda, como subproduto necessário, um modo inovador de documentar e divulgar os resultados, baseado numa combinação de técnicas cartográficas com os resultados da pesquisa de antropologia visual, que apelam para um suporte hipermídia, preferencialmente disponível na web. Desta forma, os resultados devem se tornar acessíveis não apenas para a comunidade de pesquisadores, mas para os profissionais e usuários dos serviços de saúde, particularmente aqueles concernidos no campo estudado. Essa devolução de uma imagem (mapa) da rede e de sua "substância" (as tecnologias da relação registradas em vídeo), bem como o resultado de uma certa produção coletiva de trajetórias, para o próprio grupo que as produz, é vista como parte inerente desta proposta e está relacionada a um dos resultados esperados. Ele está 
fundado na hipótese teórica de que esta devolução teria efeitos potencializadores da Inteligência Coletiva agenciada pelos dispositivos em questão.

\section{Considerações finais}

Tratamos neste artigo da emergência de um campo transdisciplinar voltado para o problema da "potência de ação coletiva" em sua estreita relação com os padrões de interação entre os indivíduos e os grupos, assim como com os processos de produção, circulação, reconhecimento e uso dos conhecimentos. Indicamos que se trata, ademais, de uma emergência epistemológica das mais inclusivas, abrangendo diversos campos disciplinares, correspondendo muito provavelmente ao fortalecimento de um paradigma de saber que não é o hegemônico. Preocupamo-nos especialmente em ressaltar os esforços que têm sido empreendidos em várias frentes das ciências humanas no sentido de buscar uma crescente formalização teórica, metodológica e das técnicas de pesquisa. A pretensão maior deste artigo, afinal, é a de partilhar com a comunidade de pesquisadores do campo da Saúde, uma tentativa contextualizada de produzir o mesmo tipo de formalização para a realização de estudos em nossa área. Acreditamos que esta iniciativa se justifica pelo caráter inaugural, prospectivo e fortemente experimental de nossa aventura científica. Se ela merece se apresentar numa etapa ainda tão preliminar é pelo que pode se beneficiar, ao atrair novos críticos e entusiastas, dos próprios mecanismos de "inteligência coletiva" operantes na comunidade científica ${ }^{5}$.

Além disso, a tentativa de produzir uma formalização científica deste tipo não dissimula as profundas motivações ético-políticas que animam este projeto. Se nos propomos a desenvolver, testar e validar critérios de avaliação do desempenho de serviços de APS da perspectiva da IC é porque nos interessa, antes de tudo, traçar esse eixo ainda não colocado para a avaliação dos serviços de saúde. Se desejamos avaliar em que medida os serviços de APS habilitam mental e afetivamente seus usuários a se porem em relação, formarem comunidades e se singularizarem existencialmente, é porque desejamos, com toda a força de nossas pulsações ético-políticas, que esses resultados da ação dos serviços sejam cada vez mais valorizados, que sejam acima de tudo tomados como um valor. A busca de uma formalização tecno-científica, portanto, não perde de vista o seu caráter de um agenciamento ético-político. E é pondo em relevo esse ponto de vista que gostaríamos de encerrar nossa intervenção.

O projeto "Acolhimento e Redes de Conversações" pode ser visto como o acionamento de um "comunoscópio" junto a um serviço de APS. Por "comunoscópio" entenda-se um dispositivo de revelação/ativação da IC dos grupos que se articulam a partir da instituição em questão. Num certo sentido, como vimos, a IC depende da rede, da malha "comunitária" a ser revelada/ativada, aquela que efetivamente processa o conhecimento coletivo. Mas sobretudo, do ponto de vista que pretendemos agora ressaltar, a IC é a operação da rede de produção biopolítica, isto é, produção "que cria não somente bens materiais, mas também relações e, em última

\author{
${ }^{5}$ Neste sentido, \\ convidamos o leitor a \\ contribuir com esse \\ projeto participando de \\ sua comunidade virtual: \\ <http://cv- \\ acolhimento.bvs.br>. \\ Ela integra o projeto de \\ desenvolvimento de \\ comunidades virtuais \\ da Biblioteca Virtual \\ em Saúde e é o \\ resultado da parceria \\ estabelecida entre a \\ BIREME/OPAS/OMS e o \\ projeto "Acolhimento e \\ Redes de Conversações \\ - o desempenho dos \\ serviços de saúde da \\ perspectiva da \\ Inteligência Coletiva" \\ (MS/CNPq, edital n०37/ \\ 2004: "Sistemas e \\ Políticas de Saúde - \\ Qualidade e \\ Humanização no sus”).
}


instância, a própria vida social” (Hardt \& Negri, 2004).

A primeira tarefa, então, do "comunoscópio" é focalizar a malha elementar de nós e conexões que compõem a rede de conversações do serviço de APS em questão.

Temos, assim, que o foco revela como nó elementar da rede não cada indivíduo, autonomamente, mas já uma relação: cada nó da rede já é uma relação, ou seja, a rede põe relações em relação. Cada nó da rede, um encontro. Ou seja, no mínimo dois corpos. O princípio de qualquer existência afetiva: a exigência de, no mínimo, dois corpos em presença. $\mathrm{O}$ princípio de qualquer conhecimento coletivo: o processamento comunicacional (conversacional) do conhecimento.

Nosso "comunoscópio" vai revelar ativando uma boa parte da rede de conversações de um serviço de APS ("boa parte" relativamente a um ponto de vista que valoriza a produção biopolítica). Conversas, trabalho afetivo, produção biopolítica. O "comunoscópio" revela ativando a IC. Impossível revelar sem se introduzir na produção biopolítica, sem operar uma alteração significativa na própria rede, sem não se tornar expansão/ reconfiguração da IC.

A "comunoscopia" é intervenção e, com certeza, tem fortes ressonâncias com várias concepções socioanalistas (análise institucional). O que ela revela, o revela para o próprio coletivo. O que ela revela deve corresponder aos elementos substantivos da rede de interações cognitivas e afetivas que sustenta aquele coletivo, que se revela para o próprio coletivo.

A hipótese assumida em bases teóricas é de que a "visão" da IC aumenta as chances daquele coletivo tornar-se inteligente, potencializar-se para a ação coletiva.

Por isso, toda "comunoscopia" é intervenção, não é simplesmente cartografar a rede e "pôr o foco das câmeras" sobre o que se passa em seus nós mais importantes, como um procedimento analítico de estudiosos "externos" à rede estudada. Isso porque as opções/construções metodológicas desenvolvidas, tanto para cartografar quanto para "focar as câmeras" nos encontros fundamentais (ou no fundamental do encontro), revelando, assim, o substrato cognitivo e afetivo do trabalho, sua processualidade propriamente coletiva, sua operação reticularizada, não o faz sem se constituir num processo de autorevelação para este coletivo, não o faz sem já se constituir num forte dispositivo de potencialização de sua IC.

É intervenção e é intervenção biopolítica. Alternativa ao biopoder e sua cultura (antidemocrática) da desconfiança. Biopolítica "menor" (contrahegemônica) de circulação de solidariedade, de confiança (no outro e na vida) e de afetos de alegria consistente. Biopolítica de restauração do vínculo social. Abertamente colocada no campo da resistência ao biopoder, hoje caracterizado pelo estado (antidemocrático) de guerra social: "Nas circunstâncias atuais, a necessidade de democracia coincide diretamente com a necessidade de paz" (Hardt \& Negri, 2004, p.90). O permanentemente colocado desafio de construção do "estado civil”, de produção do "comum", enquanto o próprio processo da nossa humanização, isto é, de busca do melhor espaço para realização das 
TEIXEIRA, R. R.

potências humanas, do melhor espaço para a singularização existencial de cada um.

Como diz, com grande força utópica, Lévy (1998, p.32-2):

Esse projeto convoca um novo humanismo que inclui e amplia o "conhece-te a ti mesmo" para um "aprendamos a nos conhecer para pensar juntos", e que generaliza o "penso, logo existo" em um "formamos uma inteligência coletiva, logo existimos eminentemente como comunidade". Passamos do cogito cartesiano ao cogitamus. Longe de fundir as inteligências individuais em uma espécie de magma indistinto, a inteligência coletiva é um processo de crescimento, de diferenciação e retomada recíproca das singularidades.

\section{Referências}

ATLAN, H. L'Organisation biologique et la théorie de l'information. Paris: Hermann, 1972.

AYRES, J.R.C.M. Sujeito, intersubjetividade e práticas de saúde. Ciênc. Saúde Colet., v.6, n.1, p.63-72, 2001.

BATESON, G. Steps to an ecology of mind. Nova York: Chandler, 1972.

CALLON, M. (Dir.) La science et ses réseaux. Paris: La Découverte, 1989.

COLEMAN, J. Foundations of social theory. Cambridge: Harvard University Press, 1990.

COSTA, R. Inteligência afluente e ação coletiva. A expansão das redes sociais e o problema da assimetria indivíduo/grupo. Razón y , n.41, 2004. Disponível em: http://www.cem.itesm.mx/dacs/ publicaciones/logos/anteriores/n41/rdacosta.html>. Acesso em: 15 mai. 2005.

DELEUZE, G.; GUATTARI, F. Mil platôs: capitalismo e esquizofrenia. São Paulo: Editora 34, 1995/1997.

FUKUYAMA, F. Confiança. Rio de Janeiro: Rocco, 1996.

GOODY, J. The logic of writing and the organization of society. Cambridge: Cambridge University Press, 1987b.

GRANOVETTER, M. Getting a job: a study of contacts and careers. Chicago: Chicago Press, 1995.

GROOTAERT, C.; NARAYAN, D.; JONES, V.N.; WOOLCOCK, M. Understanding and measuring social capital: a synthesis of findings and recommendations from the social capital initiative. 2003. Disponível em: <http://www1.worldbank.org/prem/poverty/scapital/index.htm>. Acesso em: 20 jun. 2005.

HARDT, M.; NEGRI, A. Multitude: guerre et démocratie à I'âge de l'empire. Paris: La Découverte, 2004.

HAVELOCK, E.A. A revolução da escrita na Grécia antiga. São Paulo/Rio de Janeiro: Editora da UNESP/Paz e Terra, 1996.

HAYEK, F. The use of knowledge in society. Am. Econ. Rev., v.35, n.4, p.519-30, 1945.

HEYLIGHEN, F. The world-wide web as a super-brain: from metaphor to model. Cybernetics and Systems '96. Singapore: World Science, 1998.

KELLY, K. Out of control: the new biology of machines, social systems and the economic world. New York: Addison Wesley, 1994.

KERCKHOVE, D. Connected intelligence. Toronto: Somerville House, 1997. 
LANGTON, C. G. (Ed.) Artificial life: proceedings of Santa Fe Institute Studies in the Sciences of Complexity. Redwood: Addison Wesley, 1989. v.6.

LATOUR, B. Ciência em ação. São Paulo: Ed. Unesp, 2000.

LEVIN, R.; LOCKE, C.; SEARLS, D.; WEINVERGER, D. O manifesto da economia digital. Campinas: Campus, 2000.

LEROI-GOURHAN, A. Le geste et la parole. Paris: Albin Michel, 1964. v.1 e 2.

LÉVY, P. Ethique de l'intelligence collective. 2002. Disponível em: <http://www.intervir.org/n3/levy/ 13.htm>. Acesso em: 22 jun. 2005.

LÉVY, P. A inteligência coletiva: por uma antropologia do ciberespaço. São Paulo: Loyola, 1998.

LÉVY, P. As tecnologias da inteligência: o futuro do pensamento na era da informática. São Paulo: Editora 34, 1993.

LÉVY, P.; AUTHIER, M. As árvores de conhecimentos. São Paulo: Escuta, 1995.

LUHMANN, N. Ecological communication. Chicago: University of Chicago Press, 1989.

MATURANA, H.; VARELA, F. El árbol del conocimiento. Santiago: Editorial Universitaria, 1984.

MCLUHAN, M. Understanding media: the extensions of man. New York: New American Library, 1964.

MENDES-GONÇALVES, R.B. Tecnologia e organização social das práticas de saúde: características tecnológicas de processo de trabalho na rede estadual de centros de saúde de São Paulo. São Paulo/Rio de Janeiro: Hucitec/ABRASCO, 1994.

MERHY, E.E. O SUS e um dos seus dilemas: mudar a gestão e a lógica do processo de trabalho em saúde (um ensaio sobre a micropolítica do trabalho vivo). In: FLEURY, S. Saúde e democracia: a luta do CEBES. São Paulo: Lemos Editorial, 1997. p.125-41.

MINSKY, M. The society of mind. New York: Simon and Schuster, 1997.

MOREY, D.; MAYBURY, M.; THURAISINGHAM, B.M. (Eds.) Knowledge management, classic and contemporary works. Cambridge: MIT Press, 2000.

OLSON, M. A lógica da ação coletiva. São Paulo: Edusp, 1999.

PUTNAM, R.; LEONARDI, R.; NANETTI, R. Making democracy work: civic traditions in modern Italy. Princeton: Princeton University Press, 1993.

ROSNAY, J. O homem simbiótico. Petrópolis: Vozes, 1997.

SCHRAIBER, L.B.; NEMES, M.I.B.; MENDES-GONÇALVES, R.B. Saúde do adulto: programas e ações na unidade básica. São Paulo: Hucitec, 1996.

SERRES, M. La communication. Paris: Minuit, 1968.

SIMONDON, G. Du mode d'existence des objets techniques. Paris: Aubier, 1958.

SPERBER, D. La contagion des idées. Paris: Odile Jacob, 1996.

STENGERS, I. L'invention des sciences modernes. Paris: La Découverte, 1993.

TEILHARD DE CHARDIN, P. Le phénomène humain. Paris: Seuil, 1955.

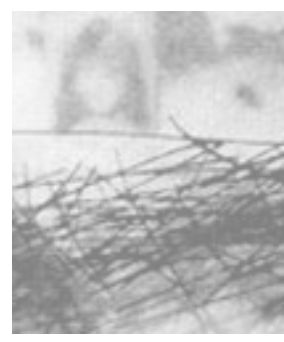

TEIXEIRA, R.R. Humanização e atenção primária à saúde. Ciênc. Saúde Colet., v.10, n.3, p.315-27, 2005. (no prelo)

TEIXEIRA, R.R. A grande saúde: uma introdução à medicina do Corpo sem Órgãos. Interface -

Comunic., Saúde, Educ., v.8, n.14, p.35-72; 2004a.

TEIXEIRA, R.R. As redes de trabalho afetivo e a contribuição da saúde para a emergência de uma 
TEIXEIRA, R. R.

outra concepção de público (working-paper). In: Research Conference on: rethinking "the Public" in Public Health: Neoliberalism, Structural Violence, and Epidemics of Inequality in Latin América. San Diego: Center for Iberian and Latin American Studies, University of California-San Diego, 2004b.

TEIXEIRA, R.R. O acolhimento num serviço de saúde entendido como uma rede de conversações. In: PINHEIRO, R.; MATTOS, R.A. (Orgs.) Construção da integralidade: cotidiano, saberes e práticas em saúde. Rio de Janeiro: IMS-UERJ/ABRASCO, 2003. p.89-111.

TEIXEIRA, R.R. Agenciamentos tecnosemiológicos e produção de subjetividade: contribuição para o debate sobre a trans-formação do sujeito na saúde. Ciênc. Saúde Colet., v.6, n.1, p.49-61, 2001.

TEIXEIRA, R.R. Árvores da Saúde - uma conversa com Pierre Lévy. Interface - Comunic., Saúde, Educ., v.3, n.4, p.143-58, 1999.

VALENTE, T.W. Social network thresholds in the diffusion of innovations. Soc. Networks, n.18, p.6989, 1996.

WASSERMAN, S.; FAUST, K. Social network analysis. Cambridge: Cambridge University Press, 1999.

WELLMAN, B.; BERKOWITZ, S. Social structures: a network approach. Cambridge: Cambridge University Press, 1988.

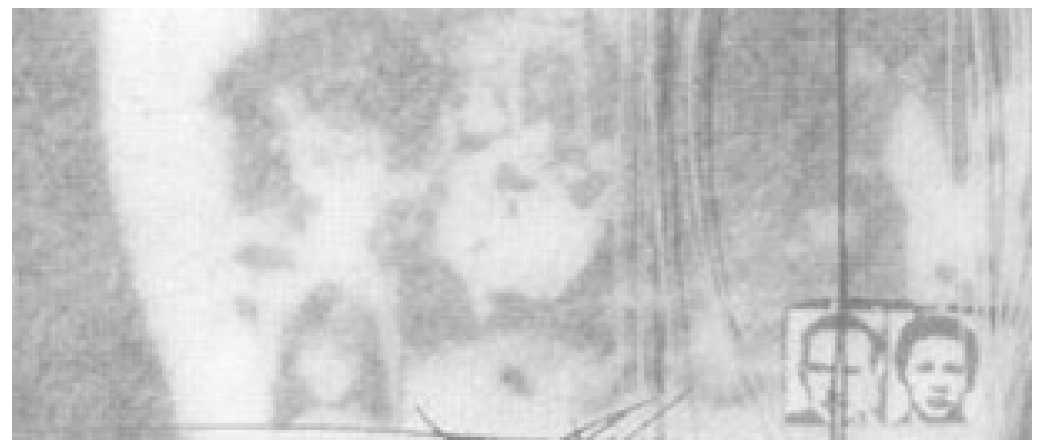

TEIXEIRA, R. R. El desempeño de un servicio de atención primaria a la salud según la perspectiva de la inteligencia colectiva. Interface - Comunic., Saúde, Educ., v.9, n.17, p.219-34, mar/ago 2005.

El objetivo de este artículo es explorar algunos posibles aportes del emergente campo de la Inteligencia Colectiva para la investigación en la Salud, en particular, para la investigación sobre la acción de los servicios de salud. Para eso se realiza una breve revisión de la literatura general y más específica sobre el asunto y de ella se extraen elementos para esbozar un primer plan de estudios de esta perspectiva en el área de la Salud. También se procura destacar la vinculación de este plan de estudios con problemas ya bien colocados en el campo de la Salud Colectiva, discutiendo, finalmente, sus implicaciones ético-políticas.

PALABRAS CLAVE: inteligencia colectiva; salud pública; servicios de salud; atención primaria de la salud.

Recebido para publicação em:26/07/05. Aprovado para publicação em: 01/08/05. 